\title{
HUBUNGAN PENGETAHUAN IBU HAMIL TENTANG ANEMIA DENGAN KEPATUHAN MEMINUM TABLET ZAT BESI DI RUMAH BERSALIN SAM KAMPUNG BARU MEDAN TAHUN 2014
}

\author{
Wildan \\ Jurusan Kebidanan Poltekkes Kemenkes Medan
}

\begin{abstract}
Abstrak
Menurut WHO kejadian anemia kehamilan berkisar 20\% sampai 89\% dengan menetapkan hemoglobin 11 gram $/ \%$ sebagai dasarnya. Hemoglobin kurang dari 11 gram/\% pada wanita hamil dapat menimbulkan dampak mulai saat dalam kandungan, setelah lahir menimbulkan masalah bagi bayi, seperti berat badan lahir rendah, penurunan status imun, kemungkinan gangguan fisiologis, dan tumbuh kembang bayi. Jenis penelitian ini bersifat analitik dengan desain penelitian cross sectional. Populasi dan sampel dari penelitian ini adalah ibu hamil sebanyak 58 orang dengan teknik accidental sampling,dengan menggunakan uji ChiSquare. Ibu berpengetahuan kurang sebanyak 22 orang (37,93\%). Responden tidak patuh mayoritas pada umur 20-35 tahun sebanyak 22 orang (56,5\%), ibu yang berpendidikan SMP sebanyak 12 orang $(66,67 \%)$, kehamilan secundipara sebanyak 12 orang $(63,15 \%)$. Hasil uji Chi-Square menyatakan ada hubungan pengetahuan dengan kepatuhan meminum tablet zat besi $\left(x^{2}=15,07\right)$, ada hubungan umur dengan kepatuhan meminum tablet zat besi $\left(\mathrm{x}^{2}=11,46\right)$, ada hubungan pendidikan dengan kepatuhan meminum tablet zat besi $\left(x^{2}=9,5\right)$, ada hubungan paritas dengan kepatuhan meminum tablet zat besi $\left(x^{2}=18,24\right)$. Ada hubngan pengetahuan ibu hamil tentang anemia kurang dan tidak patuh dalam meminum tablet zat besi.saran:kepada ibu hamil untuk lebih banyak mendapatkan informasi tentang anemia, dan patuh untuk meminum tablet zat besi.
\end{abstract}

Kata Kunci : Pengetahuan, Kepatuhan dan Tablet Besi

\section{PENDAHULUAN}

Upaya pemerintah dalam mengatasi anemia defisiensi besi ibu hami terfokus pada pemberian tablet tambah darah (Fe) pada ibu hamil. Departemen Kesehatan masih terus melaksanakan program penanggulangan anemia defisiensi besi pada ibu hamil dengan membagikan tablet besi atau tablet tambah darah kepada ibu hamil sebanyak satu tablet setiap satu hari berturut-turut selama 90 hari selama masa kehamilan (Depkes RI 2010).

Salah satu faktor yang menyebabkan masih tingginya anemia defisiensi besi pada ibu hamil adalah rendahnya kepatuhan ibu hamil dalam mengkonsumsi tablet besi. Sebanyak 74,16\% ibu hamil dinyatakan tidak patuh dalam mengkonsumsi tablet besi (Indreswari, 2008).

Hasil penelitian Budi Iswanto di Puskesmas Karangdowo, Klaten dimana pengetahuan tentang anemia defisiensi besi bahwa ibu hamil yang menjadi responden mempunyai pengetahuan tentang anemia defisiensi besi dalam kategori cukup sebesar 47 responden $(53,4 \%)$ dan yang termasuk kategori baik sebesar 14 responden $(15,6 \%)$. Sedangkan ibu hamil dengan kategori kurang sebesar 27 responden (30,0\%). Dan tingkat kepatuhan ibu hamil dalam mengkonsumsi tablet besi dengan kategori patuh sebayak 47 responden $(53,41 \%)$. Ibu hamil yang tidak patuh dalam mengkonsumsi tablet besi sebanyak 41 responden $(46,59 \%)$.
Kepatuhan dalam mengkonsumsi tablet besi adalah ketaatan ibu hamil melaksanakan anjuran petugas kesehatan untuk mengkonsumsi tablet zat besi. Kepatuhan mengkonsumsi tablet zat besi di ukur dari ketepatan jumlah tablet yang dikonsumsi, ketepatan cara mengkonsumsi tablet zat besi, frekuensi konsumsi perhari. Suplementasi besi atau pemberian tablet Fe merupakan salah satu upaya penting dalam mencegah dan menanggulangi anemia, khususnya anemia kekurangan besi. Ketidakpatuhan ibu hamil meminum tablet zat besi dapat memiliki peluang yang lebih besar untuk terkena anemia (Hidayah, 2012).

Berdasarkan survei anemia yang dilaksanakan tahun 2005 di 4 kab/kota di Sumatera Utara, yaitu Kota Medan, Binjai, Kab. Deli Serdang dan Langkat, diketahui bahwa 40,50\% pekerja wanita menderita anemia. Salah satu upaya yang dilakukan untuk menurunkan prevalensi anemia adalah dengan pemberian tablet besi $(\mathrm{Fe})$ sebanyak 90 tablet selama masa kehamilan. Cakupan ibu hamil yang mendapat 90 tablet besi di Sumatera Utara menunjukkan kenaikan yaitu $62,22 \%$ pada tahun 2010 menjadi $75,15 \%$ pada tahun 2011 dan 77,37\% pada tahun 2012. Peningkatan ini belum mampu mencapai target nasional yaitu $80 \%$ (Profil Kesehatan Sumatera Utara, 2012).

Menurut WHO kejadian anemia kehamilan berkisar $20 \%$ sampai $89 \%$ dengan menetapkan 
hemoglobin 11 gram/\% sebagai dasarnya. Berbagai negara, termasuk di Asia Tenggara diperkirakan terdapat 24.800 ribu wanita hamil yang menderita anemia dan sebagian besar menderita defisiensi besi dan di Indonesia angka prevalensi rata-rata anemia pada wanita hamil sekitar $63,5 \%$, dan $20 \%$ di antaranya adalah ADB (Anemia Defisiensi Besi) menepati urutan pertama (Ani, 2013).

Berbagai studi melaporkan bahwa ADB (Anemia Defisiensi Besi) pada wanita hamil dapat menimbulkan dampak mulai saat dalam kandungan, setelah lahir, usia sekolah hingga masa dewasa. Salah satu dampak ADB (Anemia Defisiensi Besi) yang lebih awal dapat diamati adalah partus prematurus, yaitu proses kelahiran bayi sebelum aterm. Keadaan ini menimbulkan masalah baru bagi bayi, seperti berat badan lahir rendah, penurunan status imun, kemungkinan gangguan fisiologis, dan tumbuh kembang bayi (Ani, 2013).

Berdasarkan survey awal yang dilakukan melalui wawancara di Rumah Bersalin SAM Kampung Baru Medan Tahun 2014 terhadap 30 orang ibu hamil, ditemukan 20 orang $(66 \%)$ tidak mengetahui tentang anemia dan tidak patuh meminum tablet zat besi sesuai dengan anjuran petugas kesehatan.

Berdasarkan uraian diatas, maka peneliti tertarik untuk melakukan penelitian mengenai "Hubungan Pengetahuan Ibu Hamil Tentang Anemia Dengan Kepatuhan Meminum Tablet Zat Besi di Klinik Bersalin SAM Kampung Baru Medan tahun 2014 ”.

\section{Rumusan Masalah}

"Bagaimana Hubungan Pengetahuan Ibu Hamil tentang Anemia dengan Kepatuhan Meminum Tablet Zat Besi di Rumah Bersalin SAM Kampung Baru Medan Tahun 2014?"

\section{Tujuan Penelitian}

mengetahui hubungan antara tingkat pengetahuan ibu hamil tentang anemia dengan kepatuhan meminum tablet zat besi di Rumah Bersalin SAM Kampung Baru Medan tahun 2014.

\section{METODE PENELITIAN}

Penelitian ini dilakukan di Klinik bersalin SAM Kampung Baru Medan. Penelitian ini dilakukan bulan Februari sampai bulan Juli 2014.

Desain dan sampel Penelitian

Populasi dalam penelitian ini adalah seluruh ibu hamil trimester II dan trimester III. Jumlah sampel dalam penelitian 58 orang. Penelitian yang digunakan bersifat analitik dengan desain "cross sectional" yaitu pengukuran variabel independen dan dependen dilakukan secara bersamaan.

\section{HASIL PENELITIAN}

Tabel 1. Distribusi Karakteristik Ibu Hamil Yang melakukan ANC di Rumah Bersalin SAM Kampung Baru Medan Tahun 2014

\begin{tabular}{|c|c|c|c|}
\hline \multirow[t]{2}{*}{ Karakteristik } & Kategori & $\mathbf{F}$ & $\%$ \\
\hline & $<20$ & 12 & 20,70 \\
\hline \multirow[t]{3}{*}{ Umur } & $20-35$ & 39 & 67,24 \\
\hline & $>35$ & 7 & 12,06 \\
\hline & SD & 9 & 15,53 \\
\hline \multirow[t]{5}{*}{ Pendidikan } & SLTP Sederajat & 18 & 31,03 \\
\hline & SLTA Sederajat & 16 & 27,58 \\
\hline & Perguruan & 15 & 25,86 \\
\hline & Tinggi & & \\
\hline & Primipara & 12 & 20,70 \\
\hline \multirow[t]{2}{*}{ Paritas } & Secundipara & 19 & 32,75 \\
\hline & Multipara & 27 & 46,55 \\
\hline Jumlah & & 58 & 100 \\
\hline
\end{tabular}

Berdasarkan tabel 1 diatas, menunjukkan karakteristik responden mayoritas berada pada umur 20-35 tahun yaitu 39 orang $(67,24 \%)$ dan mayoritas berpendidikan SLTP sederajat yaitu 18 orang $(31,03 \%)$. Dilihat dari paritas, mayoritas dengan paritas multipara yaitu 27 orang $(46,55 \%)$.

Tabel 2. Distribusi $\quad$ Frekuensi Berdasarkan Pengetahuan Responden Tentang Anemia Ibu Hamil di Rumah Bersalin SAM Kampung Baru Medan Tahun 2014

\begin{tabular}{lcc}
\hline Pengetahuan & F & \% \\
\hline Baik & 15 & 25,86 \\
Cukup & 21 & 36,21 \\
Kurang & 22 & 37,93 \\
\hline Jumlah & $\mathbf{5 8}$ & $\mathbf{1 0 0}$ \\
\hline
\end{tabular}

Berdasarkan tabel 2 diatas, diketahui bahwa dari 58 responden, mayoritas mempunyai pengetahuan kurang yaitu 22 orang $(37,93 \%)$, dan minoritas responden berpengetahuan baik yaitu 15 orang $(25,86 \%)$.

\section{Kepatuhan}

Tabel 3. Distribusi Frekuensi Berdasarkan Kepatuhan Responden Meminum Tablet Zat Besi Dalam Kehamilan di Rumah Bersalin SAM Kampung Baru Medan Tahun 2014

\begin{tabular}{l|c|c}
\hline Kepatuhan & F & \% \\
\hline Patuh & 34 & 58,62 \\
Tidak Patuh & 24 & 41,38 \\
\hline Jumlah & $\mathbf{5 8}$ & $\mathbf{1 0 0}$ \\
\hline
\end{tabular}

Berdasarkan tabel 3 diatas, diketahui bahwa dari 58 responden, mayoritas patuh yaitu 34 orang $(58,62 \%)$, dan minoritas responden tidak patuh yaitu 24 orang $(41,38 \%)$. 
Tabel 4. Hubungan Pengetahuan Ibu Hamil Tentang Anemia Dengan Kepatuhan Meminum Tablet Zat Besi Di Rumah Bersalin SAM Kampung Baru Medan Tahun 2014

\begin{tabular}{|c|c|c|c|c|c|c|}
\hline \multirow[t]{3}{*}{ engetahua } & \multicolumn{2}{|c|}{$\begin{array}{l}\text { Kepatuhan } \\
\mathbf{x}^{2} \text { Tabel }\end{array}$} & \multicolumn{3}{|c|}{ Total } & \\
\hline & Patuh & \multicolumn{2}{|c|}{ Tidak patuh } & \multicolumn{2}{|c|}{ Hitung } & \\
\hline & $\mathbf{F}$ & $\mathbf{F}$ & $\%$ & $\mathbf{F}$ & $\%$ & \\
\hline $\mathbf{1} \mathbf{k}$ & 12 & 3 & 20 & 15 & 100 & \\
\hline Cukup & $18 \quad 85,72$ & 3 & 14,28 & 21 & 100 & 15,07 \\
\hline Kurang & $4 \quad 18,18$ & 18 & 81,82 & 22 & 100 & 5,991 \\
\hline
\end{tabular}

Dari tabel 4 dapat diketahui bahwa hubungan pengetahuan ibu dengan kepatuhan meminum tablet zat besi dengan mayoritas patuh sebanyak 18 orang $(85,72 \%)$ yang berpengetahuan cukup dan minoritas patuh sebanyak 4 orang $(18,18 \%)$ yang berpengetahuan kurang. Mayoritas tidak patuh sebanyak 18 orang $(81,82 \%)$ berpengetahuan kurang dan minoritas 3 orang $(14,28 \%)$ yang berpengetahuan cukup.

Berdasarkan hasil uji Chi-Square $\left(\mathrm{x}^{2}\right)$ dengan $\alpha=$ 0,05 maka diperoleh nilai $\mathrm{df}=2$ hasil $\mathrm{x}^{2}$ hitung adalah 15,07 dan hasil $\mathrm{x}^{2}$ tabel adalah 5,991 Dimana $\mathrm{x}^{2}$ hitung lebih besar dari $x^{2}$ tabel $(15,07>5,991)$ yang berarti terdapat hubungan pengetahuan dengan kepatuhan meminum tablet zat besi.

Tabel 5. Hubungan Umur dengan Kepatuhan Meminum Tablet Zat Besi di Rumah Bersalin SAM Kampung Baru Medan tahun 2014

\begin{tabular}{|c|c|c|c|c|c|c|c|c|}
\hline & \multicolumn{3}{|c|}{ Kepatuhan } & Total & & $\mathrm{x}^{2}$ & \multicolumn{2}{|l|}{$\mathrm{x}^{2}$ Tabel } \\
\hline \multirow[t]{2}{*}{$\overline{\text { Umur }}$} & & & $\begin{array}{r}\mathbf{T} \\
\mathbf{P a t}\end{array}$ & & Hit & & & \\
\hline & $\mathbf{F}$ & $\%$ & $\mathbf{F}$ & $\%$ & $\mathbf{F}$ & $\%$ & & \\
\hline$<20$ tahun & 11 & 91,6 & 1 & 8,4 & 12 & 100 & & \\
\hline 20-35 tahun & 17 & 43,5 & 22 & 56,5 & 39 & 100 & 11,46 & 5,991 \\
\hline$>35$ tahun & 6 & 85,7 & 1 & 14,3 & 7 & 100 & & \\
\hline
\end{tabular}

Dari tabel 5 dapat diketahui bahwa hubungan umur ibu dengan kepatuhan meminum tablet zat besi mayoritas yang patuh pada umur 20-35 tahun sebanyak 17 orang $(43,5 \%)$ dan minoritas yang patuh pada umur $>35$ tahun sebanyak 6 orang $(85,7 \%)$. Mayoritas ibu tidak patuh pada umur 20-35 tahun sebanyak 22 orang (56,5\%) dan minoritas ibu yang tidak patuh pada umur $>35$ tahun sebanyak 1 orang $(14,3 \%)$.

Berdasarkan hasil uji Chi-Square $\left(\mathrm{x}^{2}\right)$ dengan $\alpha=$ 0,05 maka diperoleh nilai $\mathrm{df}=2$ hasil $\mathrm{x}^{2}$ hitung adalah 11,46 dan hasil $x^{2}$ tabel adalah 5,991 Dimana $x^{2}$ hitung lebih besar dari $x^{2}$ tabel $(11,46>5,991)$ yang berarti terdapat ada hubungan umur ibu hamil dengan kepatuhan meminum tablet zat besi.
Tabel 6. Hubungan Pendidikan dengan Kepatuhan Meminum Tablet Zat Besi di Rumah Bersalin SAM Kampung Baru Medan Tahun 2014

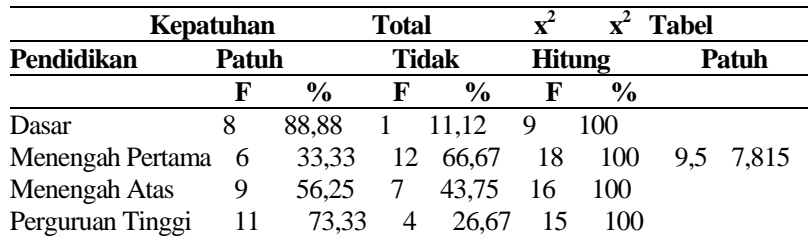

Dari tabel 6 dapat diketahui bahwa hubungan pendidikan ibu dengan kepatuhan meminum tablet zat besi mayoritas patuh yang memiliki pendidikan perguruan tinggi sebanyak 11 orang $(73,33 \%)$ dan minoritas ibu yang patuh yang berpendidikan menengah pertama sebanyak 6 orang (33,33\%). Mayoritas ibu tidak patuh yang berpendidikan menengah pertama sebanyak 12 orang $(66,67 \%)$ dan minoritas ibu tidak patuh yang berpendidikan dasar sebanyak 1 orang $(11,12 \%)$.

Berdasarkan hasil uji Chi-Square $\left(\mathrm{x}^{2}\right)$ dengan $\alpha=$ 0,05 maka diperoleh nilai $\mathrm{df}=3$ hasil $\mathrm{x}^{2}$ hitung adalah 9,5 dan hasil $\mathrm{x}^{2}$ tabel adalah 7,815 Dimana $\mathrm{x}^{2}$ hitung lebih besar dari $\mathrm{x}^{2}$ tabel $(9,5>7,815)$ yang berarti terdapat hubungan pendidikan ibu dengan kepatuhan meminum tablet zat besi.

Tabel 7. Hubungan Paritas dengan Kepatuhan Meminum Tablet Zat Besi di Rumah Bersalin SAM Kampung Baru Medan Tahun 2014

\begin{tabular}{lcccccccc}
\hline & Kepatuhan & Total & $\mathbf{x}^{2}$ & \multicolumn{2}{c}{$\mathbf{x}^{2}$ Tabel } \\
\hline Paritas & Patuh & $\begin{array}{c}\text { Tidak } \\
\text { Patuh }\end{array}$ & \multicolumn{2}{c}{ Hitung } & \\
\hline & \multicolumn{1}{c}{ P } & \% & $\mathbf{F}$ & $\mathbf{\%}$ & $\mathbf{F}$ & $\mathbf{\%}$ & & \\
\hline Primipara & 10 & 83,33 & 2 & 16,67 & 12 & 100 & & \\
Secundipara & 7 & 36,85 & 12 & 63,15 & 19 & 100 & 18,24 & 5,991 \\
Multipara & 17 & 62,97 & 10 & 37,03 & 27 & 100 & & \\
\hline
\end{tabular}

Dari tabel 7 dapat diketahui bahwa hubungan paritas ibu dengan kepatuhan meminum tablet zat besi adalah mayoritas ibu yang patuh pada ibu multipara sebanyak 17 orang $(62,97 \%)$ dan minoritas ibu yang patuh pada ibu secundipara sebanyak 7 orang $(36,85 \%)$. Mayoritas ibu tidak patuh pada ibu secundipara sebanyak 12 orang $(63,15 \%)$ dan minoritas ibu tidak patuh pada primipara sebanyak 2 orang $(16,67 \%)$.

Berdasarkan hasil uji Chi-Square $\left(\mathrm{x}^{2}\right)$ dengan $\alpha=$ 0,05 maka diperoleh nilai $\mathrm{df}=2$ hasil $\mathrm{x}^{2}$ hitung adalah 18,24 dan hasil $x^{2}$ tabel adalah 5,991 Dimana $x^{2}$ hitung lebih besar dari $x^{2}$ tabel $(18,24>5,991)$ yang berarti terdapat hubungan paritas ibu dengan kepatuhan meminum tablet zat besi.

\section{Pembahasan}

Tingkat Pengetahuan Responden

Pengetahuan memiliki konstribusi yang penting terhadap pemahaman dan penguasaan dalam hal gizi dalam kehamilan. Berdasarkan hasil penelitian dari 58 responden diketahui bahwa mayoritas pengetahuan responden memiliki tingkat pengetahuan kurang yaitu 22 orang 
$(37,93 \%)$ dan minoritas dengan pengetahuan baik yaitu 15 orang $(25,86 \%)$.

Pengetahuan sesuai teori Notoatmojo (2012), merupakan hasil dari tahu dan ini terjadi setelah orang melakukan pengindraan terhadap suatu objek tertentu. Oleh sebab itu, tahu merupakan tingkat pengetahuan yang paling rendah.

Menurut asumsi peneliti, responden kurang dalam mengetahui tentang meminum tablet zat besi. Ini dikarenakan ibu kurang mengikuti penyuluhan-penyuluhan yang dilakukan petugas kesehatan, ibu kurang mengerti pentingnya tablet besi dalam kehamilan sehingga ibu tidak patuh meminum tablet zat besi.

\section{Tingkat Kepatuhan Responden}

Berdasarkan hasil penelitian dari 58 responden diketahui bahwa mayoritas responden patuh sebanyak 34 orang $(58,62 \%)$ dan minoritas tidak patuh sebanyak 24 orang $(41,38 \%)$.

Umur adalah umur individu yang terhitung mulai saat dilahirkan sampai berulang tahun. Semakin cukup umur, tingkat kematangan dan kekuatan seseorang akan lebih matang dalam berpikir dan bekerja (Wawan, 2010).

Paritas adalah banyaknya jumlah anak yang dilahirkan oleh ibu. Jumlah anak dilahirkan merupakan salah satu faktor yang mempengaruhi pengetahuan ibu tentang meminum tablet zat besi. Pada umumnya ibu yang memilki anak lebih dari satu memilki pengetahuan lebih baik dibandingkan yang baru pertama kali melahirkan, pengetahuan tersebut dikarenakan pengalaman melahirkan (Lilis, 2009).

Hasil penelitian Sadariah tahun 2012, di Puskesmas Bara-Baraya diperoleh bahwa dari 110 sampel ibu hamil terdapat $43(39,9 \%)$ ibu hamil yang menderita anemia didapatkan $16(37,2 \%)$ ibu yang tidak patuh dalam konsumsi tablet zat besi. Tingkat pengetahuan seseorang mengenai tablet Fe berpengaruh terhadap perilaku dalam memilih makanan yang mengandung zat besi. Hal ini sejalan juga dengan penelitian yang dilakukan oleh Sri (2006) di Bantul, menyebutkan bahwa ibu hamil yang memiliki pengetahuan mengenai anemia yang cukup baik belum dapat mendorong ibu hamil untuk lebih patuh mengonsumsi tablet $\mathrm{Fe}$ akan tetapi terdapat kecenderungan bahwa sebagian besar ibu hamil yang patuh memiliki pengetahuan yang baik.

Menurut asumsi peneliti, kepatuhan ibu meminum tablet zat besi sangat dipengaruhi dengan pengetahuan ibu. Karena semakin baik pengetahuan ibu maka akan semakin patuh ibu meminum tablet zat besi dalam kehamilan. Kurangnya kepatuhan ibu meminum tablet zat besi dapat juga dipengaruhi umur, karena semakin cukup umur tingkat kematangan ibu akan lebih baik dalam berfikir dan patuh meminum tablet zat besi. Pendidikan, karena tingkat pendidikan ibu yang rendah dapat mengakibatkan kurangnya pengetahuan dan kepatuhan ibu dalam meminum tablet zat besi. Dan paritas, karena pengalaman ibu memiliki anak lebih dari satu memiliki pengetahuan dan kepatuhan dalan meminum tablet zat besi.

\section{Hubungan Kepatuhan Terhadap Umur}

Dari hasil penelitian diketahui bahwa mayoritas responden tidak patuh meminum tablet zat besi banyak terdapat pada umur 20-35 sebanyak 22 orang (56,5\%).

Berdasarkan hasil uji Chi-Square $\left(\mathrm{x}^{2}\right)$ dengan $\alpha$ $=0,05$ maka diperoleh nilai $\mathrm{df}=2$ hasil $\mathrm{x}^{2}$ hitung adalah 11,46 dan hasil $\mathrm{x}^{2}$ tabel adalah 5,991 Dimana $\mathrm{x}^{2}$ hitung lebih besar dari $x^{2}$ tabel $(11,46>5,991)$ yang berarti terdapat ada hubungan umur ibu hamil dengan kepatuhan meminum tablet zat besi.

Pada penelitian ini belum menunjukkan adanya kecenderungan semakin tua usia ibu hamil maka anemia semakin besar. Hasil penelitian ini sama dengan penelitian yang dilakukan Herlina yang menunjukkan bahwa hubungan yang tidak bermakna antara usia ibu hamil dengan anemia ( $p>0.05$ ). Sedangkan pada penelitian Gautam menunjukkan adanya hubungan yang bermakna ( $p$ $<0,05)$.

Menurut asumsi peneliti bahwa umur ibu sangat berpengaruh dengan tidak patuhnya meminum tablet zat besi pada ibu hamil. Umur ibu <20 tahun kurang perhatian dengan kesehatannya dan kurang peduli dengan kehamilannya dimana ibu tidak mengetahui tentang pentingnya tablet zat besi sehingga tidak patuh meminum tablet zat besi, umur 20-35 tahun adalah umur sehat dan aman bagi ibu dimana pengetahuan ibu cukup, sehingga patuh meminum tablet zat besi sedangkan umur $>35$ tahun umur yang rentan berbahaya karena sering lupa meminum tablet zat besi dan ibu pun menjadi tidak patuh.

\section{Hubungan Kepatuhan Terhadap Pendidikan}

Dari hasil penelitian diketahui bahwa responden yang patuh meminum tablet zat besi mayoritas yaitu ibu yang pada pendidikan perguruan tinggi sebanyak 11 orang $(73,33 \%)$ dan minoritas pendidikan dasar sebanyak 1 orang $(11,12 \%)$ ibu tidak patuh meminum tablet zat besi.

Berdasarkan hasil uji Chi-Square $\left(\mathrm{x}^{2}\right)$ dengan $\alpha=$ 0,05 maka diperoleh nilai $\mathrm{df}=3$ hasil $\mathrm{x}^{2}$ hitung adalah 9,5 dan hasil $\mathrm{x}^{2}$ tabel adalah 7,815 Dimana $\mathrm{x}^{2}$ hitung lebih besar dari $x^{2}$ tabel $(9,5>7,815)$ yang berarti terdapat hubungan pendidikan ibu dengan kepatuhan meminum tablet zat besi.

Menurut asumsi penulis, dari hasil penelitian yang telah dilakukan bahwa responden yang berpendidikan tinggi lebih mudah menerima dan melakukan saran maupun informasi tentang pentingnya zat besi sehingga lebih patuh dalam mengkonsumsinya, namun hasil penelitian masih ditemukan ibu yang berpendidikan tinggi tidak patuh dalam meminum tablet zat besi. Hal ini dikarenakan ibu tidak peduli pentingnya meminum tablet zat besi dan tidak mengikuti penyuluhan yang dilakukan oleh petugas kesehatan sehingga ibu tidak patuh meminum tablet zat besi.

\section{Hubungan Kepatuhan Terhadap Paritas}

Dari hasil penelitian diketahuai bahwa responden yang patuh meminum tablet zat besi mayoritas yaitu multipara sebanyak 17 orang $(62,96 \%)$ dan minoritas primipara sebanyak 2 orang $(16,67 \%)$ ibu tidak patuh meminum tablet zat besi. 
Berdasarkan hasil uji Chi-Square $\left(\mathrm{x}^{2}\right)$ dengan $\alpha=$ 0,05 maka diperoleh nilai $\mathrm{df}=2$ hasil $\mathrm{x}^{2}$ hitung adalah 18,24 dan hasil $x^{2}$ tabel adalah 5,991 Dimana $x^{2}$ hitung lebih besar dari $x^{2}$ tabel $(18,24>5,991)$ yang berarti terdapat hubungan paritas ibu dengan kepatuhan meminum tablet zat besi.

Menurut asumsi peneliti dalam penelitian ini, paritas sangat berhubungan terhadap kepatuhan meminum tablet zat besi karena semakin sering ibu melahirkan semakin banyak pengalaman dan pengetahuan dalam meminum tablet zat besi selama kehamilan sehingga ibu patuh meminum tablet zat besi.

Manfaat meminum tablet zat besi anak yg dilahirkan sehat dibanding anak sebelumnya yang dilahirkan yg tidak patuh meminum tablet zat besi, dan ibu pun saat hamil tidak mengalami pusing seperti yang di alaminya pada hamil pertama.

\section{KESIMPULAN DAN SARAN}

\section{Kesimpulan}

Berdasarkan hasil pembahasan penelitian yang berjudul "Hubungan Pengetahuan Ibu Hamil Tentang Anemia Dengan Kepatuhan Meminum Tablet Zat Besi Di Rumah Bersalin SAM Kampung Baru Medan Tahun 2014', maka dapat diambil kesimpula sebagai berikut :

1. Ada hubungan tingkat pengetahuan ibu hamil tentang anemia dengan kepatuhan meminum tablet zat besi.

Dari hasil uji Chi-Square $\left(\mathrm{x}^{2}\right)$ dimana $\mathrm{x}^{2}$ hitung lebih besar dari $x^{2}$ tabel $(15,07>5,991)$ yang berarti terdapat hubungan pengetahuan dengan kepatuhan meminum tablet zat besi.

2. Ada hubungan kepatuhan ibu hamil meminum tablet zat besi berdasarkan umur. Dari hasil uji Chi-Square $\left(\mathrm{x}^{2}\right)$ dimana $\mathrm{x}^{2}$ hitung lebih besar dari $\mathrm{x}^{2}$ tabel $(11,46>5,991)$ yang berarti terdapat hubungan umur dengan kepatuhan meminum tablet zat besi.

3. Ada hubungan kepatuhan ibu hamil meminum tablet zat besi berdasarkan pendidikan.

Dari hasil uji Chi-Square $\left(\mathrm{x}^{2}\right)$ dimana $\mathrm{x}^{2}$ hitung lebih besar dari $x^{2}$ tabel $(9,5>7,815)$ yang berarti terdapat hubungan pendidikan dengan kepatuhan meminum tablet zat besi.

4. Ada hubungan kepatuhan ibu hamil meminum tablet zat besi berdasarkan paritas.

Dari hasil uji Chi-Square $\left(\mathrm{x}^{2}\right)$ dimana $\mathrm{x}^{2}$ hitung lebih besar dari $\mathrm{x}^{2}$ tabel $(18,24>5,991)$ yang berarti terdapat hubungan paritas dengan kepatuhan meminum tablet zat besi.

\section{Saran}

1. Bagi pimpinan Rumah Bersalin SAM

Diharapkan kepada petugas kesehatan untuk memberikan penyuluhan kepada ibu hamil tentang anemia dalam kehamilan sehingga ibu hamil dapat patuh dalam meminum tablet zat besi, ibu berpendidikan rendah pun dapat di beri penjelasan tentang anemia agar ibu tersebut patuh dalam meminum tablet zat besi yang di berikan oleh tenaga kesehatan, begitu juga terhadap ibu yang hanya mempunyai satu anak, sehingga kurang dalam mempunyai pengalaman, ibu dapat di beri penjelasan agar bayi ibu dan ibu akan lebih sehat bila mengkonsumsi tablet zat besi dan patuh meminumnya.

2. Bagi ibu hamil

Agar lebih sering mengikuti berbagai penyuluhan oleh tenaga kesehatan, dan menggali informasi dari media masa tentang pentingnya meminum tablet zat besi sehingga ibu patuh dalam meminum tablet zat besi.

\section{DAFTAR PUSTAKA}

Ahmad N, Kalakoti P, Bano R, Aarif SM. The prevalence of anaemia and associated factors in pregnant women in a rural Indian community. Australasian Medical Journal. 2010; 3,5, 276280. Diunduh 29 Juli 2014

Almatsier. 2010. Prinsip Dasar Ilmu Gizi. Gramedia Pustaka Utama. Jakarta

Ani. 2013. Buku Saku Anemia Defisiensi Besi. EGC. Jakarta

Depkes RI, 2010, Profil Kesehatan Indonesia 2009, Jakarta, p. 106-7. www.DepkesRI.com

Depkes. 2012. Profil Kesehatan Indonesia Tahun 2012. Jakarta : Depkes http://www.depkes.go.id/downloads/publikasi/P rofil\%20Kesehatan\%20Indonesia\%202008.pdf Diunduh 7 Mei 2014

Depkes, RI. 2013. Panduan Penyusunan Karya Tulis Ilmiah, Politeknik Kesehatan Kemenkes Medan

Elvina. 2012. Artikel Kesehatan Waspada Anemia Saat Hamil.

http://health.okezone.com/read/2012/09/09/483/ 687153/waspada-anemia-saat-hamil, Sindo. Rabu, 9 September 2012. 07.45 Wib. Diunduh Selasa, 14 Januari 2014

Indreswari, dkk 2008, Hubungan antara Intensitas Pemeriksaan Kehamilan, Fasilitas Pelayanan Kesehatan, dan Konsumsi Tablet Besi dengan Tingkat Keluhan selama Kehamilan. Jurnal Gizi dan Pangan.

Notoatmojo. 2010. Metode Penelitian Kesehatan. Rineka Cipta. Jakarta

Proverawati, A. 2011. Anemia dan Anemia Kehamilan. Nuha Medika. Yogyakarta

Sulistyoningsih, H. 2011. Gizi Untuk Kesehatan Ibu dan Anak. Graha Ilmu. Yogyakarta

Susilawati. 2011. Hubungan Pengetahuan dan sikap dengan kepatuhan mengkonsumsi tablet zat besi folat pada ibu hamil dengan kejadian anemia gravidarum di Puskesmas Jabon Jombang. [Tesis]. Surakarta : Universitas Sebelas Maret Surakarta. Diunduh 29 Juli 2014

Wawan dan Dewi M. 2011. Pengetahuan, Sikap, dan Perilaku Manusia. Nuha Medika. Yogyakarta. 